\title{
Anodic Coating Characteristics of Different Aluminum Alloys for Spacecraft Materials Applications
}

\author{
Afaf M. Abd El-Hameed1, Yehia A. Abdel-Aziz¹, Fatma S. El-Tokhy² \\ ${ }^{1}$ National Research Institute of Astronomy and Geophysics (NRIAG), Cairo, Egypt \\ ${ }^{2}$ Faculty of Engineering, El-Zagazig University, Zagazig, Egypt \\ Email: mostafaafaf2000@yahoo.com, yehia@nriag.sci.eg
}

How to cite this paper: El-Hameed, A.M.A., Abdel-Aziz, Y.A. and El-Tokhy, F.S. (2017) Anodic Coating Characteristics of Different Aluminum Alloys for Spacecraft Materials Applications. Materials Sciences and Applications, 8, 197-208.

https://doi.org/10.4236/msa.2017.82013

Received: December 12, 2016

Accepted: February 5, 2017

Published: February 8, 2017

Copyright $\odot 2017$ by authors and Scientific Research Publishing Inc. This work is licensed under the Creative Commons Attribution International License (CC BY 4.0). http://creativecommons.org/licenses/by/4.0/

\section{Open Access}

\begin{abstract}
Anodic oxide coatings on aluminum alloys are used for space environment applications. These provide specific thermo-optical properties to spacecraft surface. Fragments of these coatings lead to generate the contamination in satellites and affect the mission lifetime. The current work concerns studying of the anodic processes applied on aluminum and different groups of aluminum alloys as Al7075, Al2024 and Al6061. Experimental procedures are performed using sulfuric acid at different values of current density $\left(1-2 \mathrm{~A} / \mathrm{dm}^{2}\right)$. The influence of the parameters of anodic film formation on the coating characteristics and layer thickness of aluminum alloys has been investigated. Reflectance and optical properties of the anodized aluminum alloy coatings are determined and found to be dependent on the alloying elements. Changes in anodic coating weight and film thickness of aluminium alloys with the process parameters as current density, temperature, time duration, acid concentration, and sealing system have been studied. Moreover, morphology and surface structure of the considered samples are carried out in attempt to understand the physical characteristics. The obtained results are compared and briefly outlined.
\end{abstract}

\section{Keywords}

Anodic Oxide Coatings, Aluminum Alloy Samples, Sulfuric Acid, Optical Properties, Morphology, Analysis

\section{Introduction}

Aluminum and aluminum alloys have many applications especially in aerospace industries because of their excellent properties such as high strength to weight 
ratios, low cost, high thermal conductivity and good corrosion resistance. Anodizing is an electrochemical process that is used to form the oxide films on the surface of metals. Anodizing process creates a hard, corrosion- and abrasion-resistant oxide coating on aluminum alloys. The anodization layer is formed to adjust and control the thermo-optical properties [1] [2] [3] [4]. Clear anodic oxide coatings have high emissivity and low absorptivity that lead to the efficient radiative heat transfer in the space environment. Aluminum and different groups of aluminum alloys (Al6061, Al2024 and Al7075) are important and widely used, which in particular satisfy the requirements of space applications with good results. As an example, after thermal cycling on aluminum alloys see that in groups $2 \mathrm{XXX}$ and 7XXX, some of these alloys have been observed. Therefore, anodizing provides the required optical properties to minimize thermal cycling temperatures and prevent overheating and undercooling in every part of equipment namely good temperature stability of onboard equipments [5] [6] [7] [8] [9]. In the International Space Station (ISS), the micrometeoroid and orbital debris shields are made from anodized aluminum because of its specific thermal properties. The anodizing process is evaluated in regard to throwing power and fatigue life [9] [10], additionally, anodic coatings can meet not only the environmental requirements but also the continual demand by aerospace and defense hardware for improved surface performance with multifunctional properties to work under extreme environmental exposures (see Figure 1) [11]. Accordingly, aluminum alloys have a good corrosion resistance for most environmental exposures. Specific environmental conditions may cause corrosion leading to degradation of the surfaces and potentially stress corrosion cracking, causing failure of aluminum alloys. Therefore, anodic coatings have been developed to protect the aluminum from corrosion and enhance the adhesion of paints and adhesives [12] [13] [14]. However, the anodic aluminum coatings mitigate the occurrence of degradation in spacecraft' surfaces due to space plasma environment effects [15] [16].

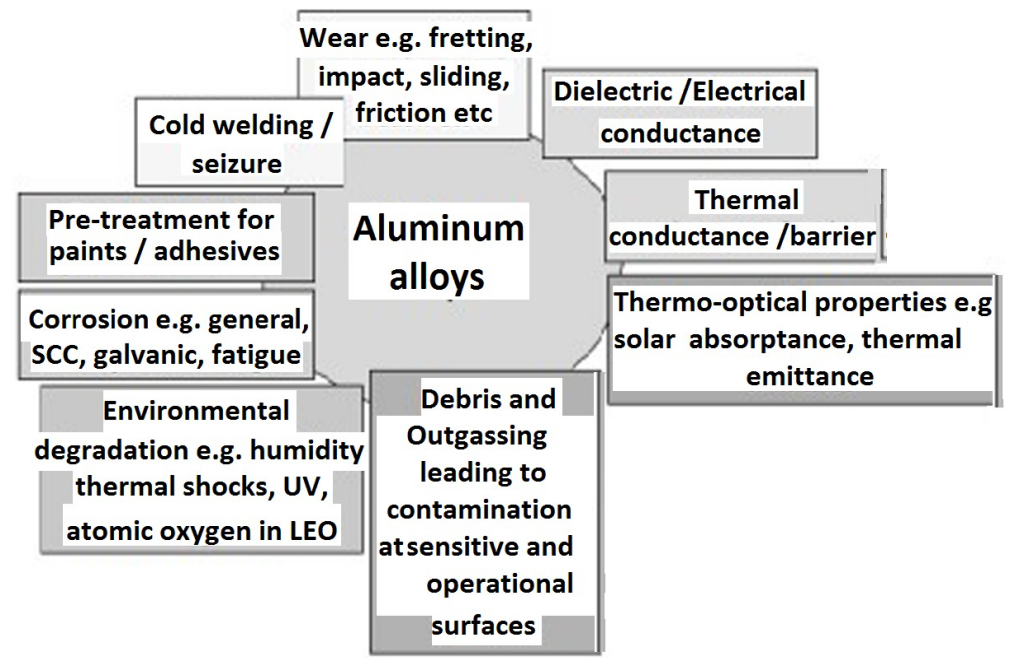

Figure 1. Multifunctional properties from surface coatings on aluminum alloys for space applications [11]. 
A wide variety of electrolytes is considered to produce anodic coating on aluminum. According to the solvent action of the electrolyte used for production the anodic film, anodic coatings can be classified. Some of these coatings are of porous and obtained as example from sulfuric electrolyte (Type II). Sulfuric acid is one of the most important anodizing processes because of the characteristics and properties of the film. Different thickness values, clear coating, colored and sealed can be easily obtained. Sulfuric acid anodizing produces coatings with less solar absorptance and high thermal emittance, so, it is common used for thermal control surfaces [17] [18] [19].

In the current research, laboratory measurements are carried out to investigate the anodic oxide films produced on aluminum layer and different samples of aluminum alloys. Sulfuric acid anodizing coatings are considered. The anodization parameters as acid concentration, temperature, current density, and sealing process, are taken into account to investigate the physical characteristics and film thickness for the considered samples. Morphology and optical analysis are used to clarify the anodic film behavior. The obtained results of the different samples are compared.

\section{Anodic Coatings}

\subsection{Anodic Technique (Oxide Film Formation)}

An electrochemical method (electrolyte solution) is used to anodize the metal surface of aluminum alloys. Because sulfuric acid (Type II) is the most widely used solution to produce anodized coating and provides most corrosion protective finish, the anodic coatings are performed at the laboratory with the concentration of sulfuric acid bath ( $\left.15 \mathrm{wt} \% \mathrm{H}_{2} \mathrm{SO}_{4}\right)$ [1] [20]. In the anodized process, the constant voltage with the value $15 \mathrm{~V}$ is applied on the circuit and two operating temperatures $\left(21^{\circ} \mathrm{C}\right.$ and $\left.35^{\circ} \mathrm{C}\right)$ are considered in the bath. The thickness coatings formed by this method varies with the anodization parameters. An electric current is introduced into the bath in which the aluminum alloy plate has been immersed. The anodization process is carried out on different types of sample plates seeing that aluminum and different groups of aluminum alloys Al6061, Al2024 and Al7075. These samples are taken with different sizes. The compositions of these alloys are given in Table 1. These materials have been used for space applications such that for spacecraft structures, flight hardware, and space devices as onboard and power systems [21]. Moreover, to clarify the impact of electrolyte concentration on the anodic film thickness, $20 \%$ by weight

Table 1. Aluminum alloys compositions.

\begin{tabular}{|c|c|}
\hline Aluminum alloy & Compositions $^{*}$ \\
\hline Al7075 & $5.5 \% \mathrm{Zn} ; 2.5 \% \mathrm{Mg} ; 1.5 \% \mathrm{Cu} ; 0.3 \% \mathrm{Cr}$ \\
\hline $\mathrm{Al} 2024$ & $\begin{array}{l}3.8 \% \text { to } 4.9 \% \mathrm{Cu} ; 1.2 \% \text { to } 1.8 \% \mathrm{Mg} ; 0.3 \% \text { to } 0.9 \% \mathrm{Mn} ; 0 \% \text { to } 0.5 \% \mathrm{Fe} ; 0 \% \text { to } \\
0.5 \% \mathrm{Si} ; 0 \% \text { to } 0.25 \% \mathrm{Zn} ; 0 \% \text { to } 0.2 \% \mathrm{Zr} ; 0 \% \text { to } 0.15 \% \mathrm{Ti} ; 0 \% \text { to } 0.1 \% \mathrm{Cr}\end{array}$ \\
\hline Al6061 & $0.8 \%$ to $1.2 \% \mathrm{Mg} ; 0.6 \% \mathrm{Si} ; 0.15 \% \mathrm{Mn} ; 0.28 \% \mathrm{Cu} ; 0.7 \% \mathrm{Fe}$ \\
\hline
\end{tabular}

*Underlines mean the majority of material compositions. 
sulfuric acid is taken in our consideration with the constant voltage $15 \mathrm{~V}$, temperature $21^{\circ} \mathrm{C}$, and current density $\left(2 \mathrm{~A} / \mathrm{dm}^{2}\right)$. These parameters are applied on the two samples Al6061, and Al2024 for time period 60 minutes of process.

\subsection{Sealing Process}

Because the coating process is highly porous and is subject to attack from the environment and corrosive elements, sealing process is required to improve surface from cracking and also to improve its resistance to corrosion. The method used to seal the anodic films of the considered samples is the hot water, in which the treated aluminum alloy is immersed in deionized water nearest to the boiling point for 15 minutes. This method may partially convert the alumina of anodic coating to aluminum mono-hydroxide. The mechanism of sealing occurred in boiling water is considered as the hydration of the anodic film. The aluminum oxide reacts with water to form aluminum hydroxide, which fills pores in the coating and seals the surface [22].

$$
\mathrm{Al}_{2} \mathrm{O}_{3}+(\mathrm{n}+1) \mathrm{H}_{2} \mathrm{O} \rightarrow 2 \mathrm{AlOOH}+n \mathrm{H}_{2} \mathrm{O} \quad(n \succ 1) .
$$

From this process, the anodic surface becomes with more flatness and uniformity. This water-sealing technique is used to seal the porous coatings to protect the substrate from attack by environment.

\section{Characteristics, Results and Analysis}

The characteristic of anodized coating layer is influenced by the process parameters as current density, temperature, and time duration. One of the most important factors is the current density applied on the samples. This factor is useful to determine the characteristic of the coated layer on aluminium alloy [23]. Two values $\left(1-2 \mathrm{~A} / \mathrm{dm}^{2}\right)$ of the current density are applied in our experiments. Another factor used in this study is the time required for occurrence the coating process. For the oxide film formation, two time intervals 30, 60 minutes are considered for taking place the anodizing process and applied on all sample plates. These values are chosen to examine its effects on the oxide coating thicknesses for different alloy materials. Table 2 gives the results of the coating thickness for the considered alloys obtained at different parameters of the anodization process. The film thickness $d$ can be calculated for the samples using the formula.

$$
d=\left(m-m_{0}\right) / \rho A
$$

where $m$ and $m_{0}$ are the weight measured for the anodized sample after and before the anodizing process respectively, obtained from the difference in mass of each sample plate before and after film deposition, $A$ is the area of film on the sample plate, and $\rho$ is the density of the anodic film of aluminium alloys.

From the results obtained in Table 2, it is clearly observed that; at the same time of process:

1) Increasing current density leads to increase the film thickness;

2) Lowering bath temperatures result in more dense coating and high thickness values. 
Table 2. The thickness values of Al-alloys.

\begin{tabular}{|c|c|c|c|c|}
\hline \multirow[t]{2}{*}{ Temp. $\left({ }^{\circ} \mathrm{C}\right)$} & \multirow[t]{2}{*}{ Time (min) } & \multirow[t]{2}{*}{ Alloys } & \multicolumn{2}{|c|}{ Coating thickness $(\mu \mathrm{m})$} \\
\hline & & & Current density $=1 \mathrm{~A} / \mathrm{dm}^{2}$ & Current density $=2 \mathrm{~A} / \mathrm{dm}^{2}$ \\
\hline \multirow{3}{*}{21} & \multirow{3}{*}{30} & 7075 & 2 & 3.22 \\
\hline & & 2024 & 3.07 & 3.8 \\
\hline & & 6061 & 5.85 & 6.55 \\
\hline \multirow{3}{*}{21} & \multirow{3}{*}{60} & 7075 & 2.66 & 3.43 \\
\hline & & 2024 & 4.07 & 5.24 \\
\hline & & 6061 & 10.8 & 13.4 \\
\hline \multirow{3}{*}{35} & \multirow{3}{*}{30} & 7075 & 1.8 & 3.12 \\
\hline & & 2024 & 2.18 & 2.7 \\
\hline & & 6061 & 5.3 & 5.65 \\
\hline
\end{tabular}

Table 3. Thickness values of Al-alloys.

\begin{tabular}{ccccc}
\hline Temp. $\left({ }^{\circ} \mathrm{C}\right)$ & Time $(\mathrm{min})$ & Current density & \multicolumn{2}{c}{ Calculated thickness for Al-alloys $(\mu \mathrm{m})$} \\
\hline \multirow{2}{*}{21} & 60 & $2 \mathrm{~A} / \mathrm{dm}^{2}$ & 6061 & 2024 \\
& & & 17.1 & 8.3 \\
\hline
\end{tabular}

The table also clarifies the increase in anodic thickness with time at the same other parameters and conditions of the experiment. These results are valid and correlated with that obtained from many studies [23] [24] [25] [26].

To verify the effect of electrolyte concentration on the anodic film thickness, Table 3 gives the film thickness obtained with $20 \mathrm{wt} \%$ sulfuric acid and with the parameters (current density $2 \mathrm{~A} / \mathrm{dm}^{2}$, temperature $21^{\circ} \mathrm{C}$ and time 60 minutes) for the aluminum alloys Al6061 and Al2024 as an example.

The obtained result shows that, for the for the same two samples considered in Table 2, the increasing of the thickness with increase in acid concentration greater than that obtained with $15 \mathrm{wt} \%$ acid concentration [27]. It is evident that, anodizing in less acid concentration is performed to obtain a considerably thin anodize layer that gives lower impact on the fatigue strength of the alloy.

\section{Sealing Effect}

After sealing process (with hot water at $98^{\circ} \mathrm{C}$ for 15 minutes) reduction in weight is observed. This is because of the loss in the thickness of anodic oxide film [14]. This loss is due to the dry air (decreasing in humidity, which leads to increasing the weight loss). Table 4 clarifies the sealing effect of the sample weight for the aluminum alloys after anodization process.

Table 5 gives an example of the measuring thickness for two samples ( $\mathrm{Al}$, and Al6061). The data interpret the decrease in thickness with sealing process for the two considered samples due to the weight loss of the anodic coating films.

\section{Optical properties}

For the alloy samples, surface structural and properties are considered to investigate the physical characteristics of the anodic films. The optical images of 
the different anodizing alloys samples are shown in Figure 2. The images show the coatings are adhered to the substrate. It is interesting to notice that, the sample Al7075 becomes opaque coloring due to the immersion in nickel. The greater opacity of anodic coating Al7075 refers to the dense surface and the alloy elements.

The optical properties of the anodized aluminum alloy coatings are determined using the instrument "SPECTROMETER/JASCO Corp., V-570, Rev. 1.00". Figure 3 shows the absorbance spectra of the anodic alloy samples Al6061 (Black) and Al2024 (Red) against the wavelength. The figure characterizes the light absorption of samples in a wide wavelength range from ultraviolet (UV) to infrared (IR) wavelengths $(200 \mathrm{~nm}-2200 \mathrm{~nm})$. The same behavior is observed for the two considered samples with increasing in values for alloy Al2024. The

Table 4. The alloy's weight without and with sealing process.

\begin{tabular}{|c|c|c|c|c|c|c|}
\hline \multirow[t]{2}{*}{ Current density } & \multirow[t]{2}{*}{ Temp. $\left({ }^{\circ} \mathrm{C}\right)$} & \multirow[t]{2}{*}{ Time $(\min )$} & \multirow[t]{2}{*}{ Alloys } & \multicolumn{2}{|c|}{ Weight after anodization } & \multirow[b]{2}{*}{$\begin{array}{c}\text { The weight } \\
\text { loss }\end{array}$} \\
\hline & & & & $\begin{array}{l}\text { Without } \\
\text { sealing }\end{array}$ & $\begin{array}{c}\text { With } \\
\text { sealing }\end{array}$ & \\
\hline \multirow{3}{*}{$1 \mathrm{~A} / \mathrm{dm}^{2}$} & \multirow{3}{*}{21} & \multirow{3}{*}{30} & 7075 & 20.41 & 20.293 & 0.117 \\
\hline & & & 2024 & 37.871 & 37.7 & 0.171 \\
\hline & & & 6061 & 20.3 & 19.592 & 0.708 \\
\hline \multirow{3}{*}{$2 \mathrm{~A} / \mathrm{dm}^{2}$} & \multirow{3}{*}{21} & \multirow{3}{*}{30} & 7075 & 20.1709 & 20.055 & 0.1159 \\
\hline & & & 2024 & 29.458 & 29.18 & 0.278 \\
\hline & & & 6061 & 19.963 & 19.619 & 0.344 \\
\hline
\end{tabular}

Table 5. Thickness of the samples with and without sealing effect.

\begin{tabular}{cccccc}
\hline Temp. $\left({ }^{\circ} \mathrm{C}\right)$ & Time $(\mathrm{min})$ & Metal/alloys & Current density & \multicolumn{2}{c}{ Measuring thickness $(\mu \mathrm{m})$} \\
\hline & & $\mathrm{A} / \mathrm{dm}^{2}$ & Without & With \\
& & & 1 & 2.6 & 1.5 \\
sealing
\end{tabular}

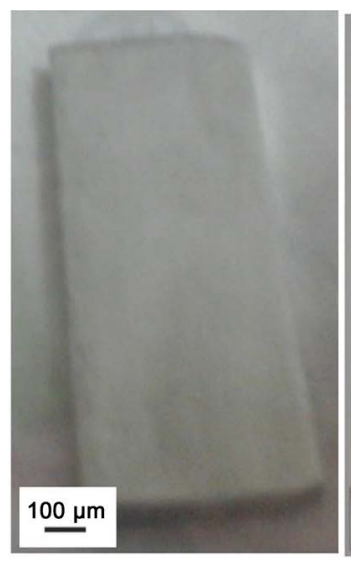

Al 6061

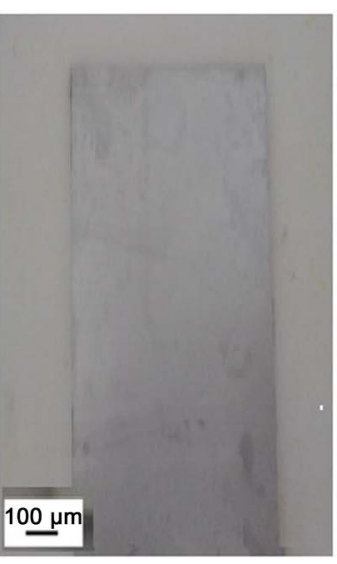

Al 2024

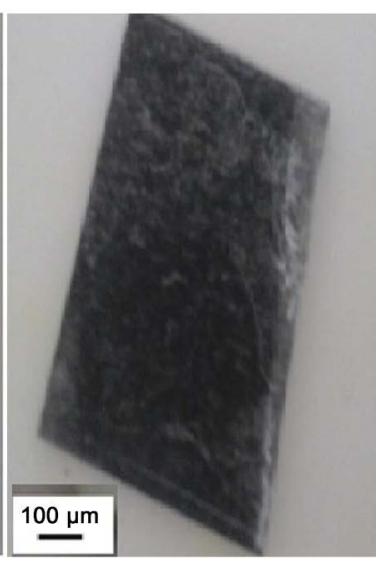

Al 7075

Figure 2. Optical images of anodizing Al-alloy samples. 


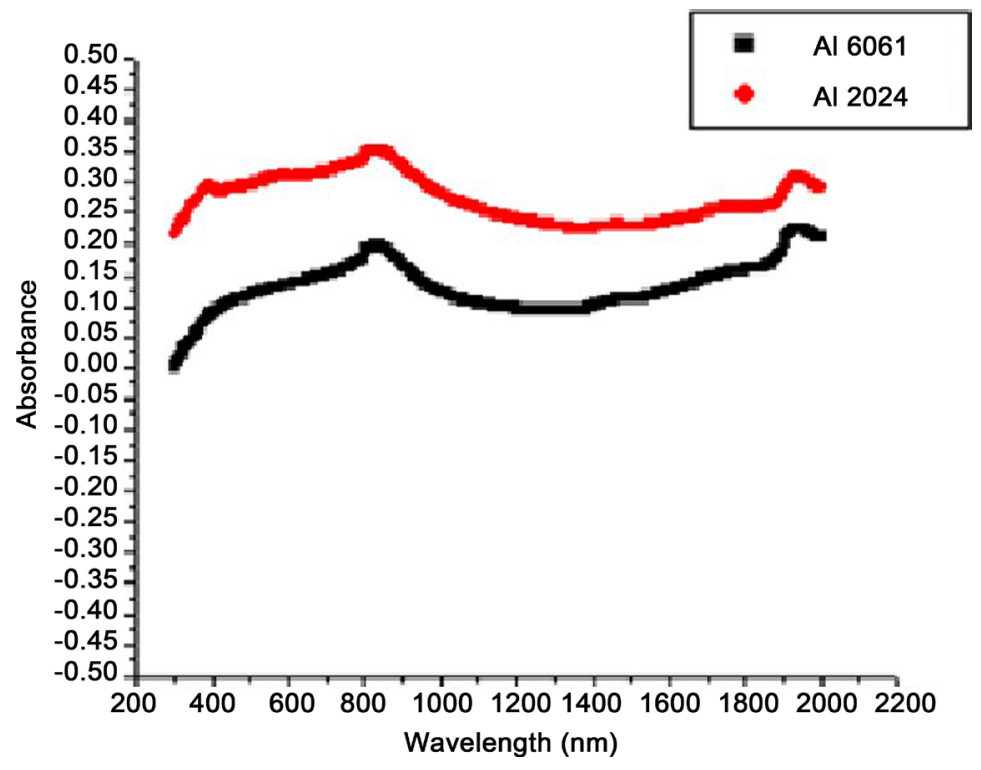

Figure 3. Absorbance of the Al-alloy samples.

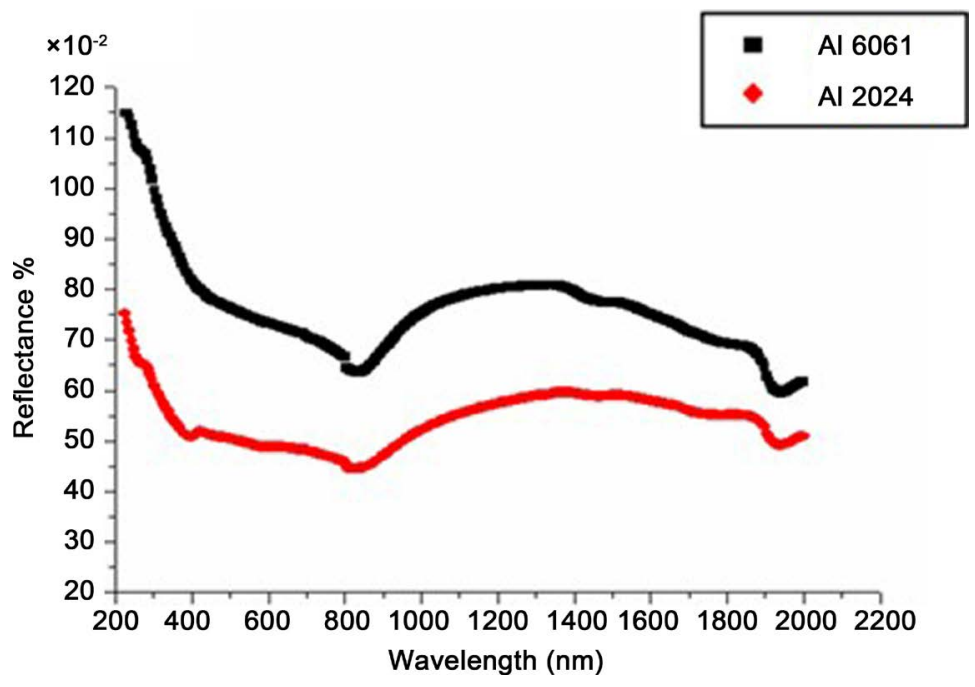

Figure 4. Reflectance of Al-alloy samples.

figure exhibits two small peaks at the wavelengths about $800 \mathrm{~nm}$ and $2000 \mathrm{~nm}$ found in the two samples. In Figure 4, it is noticed that, from the percent reflectance, the inverse trend is observed. Also the same manner of the two samples is obtained with the decreasing values for alloy Al2024.

These behaviors are comparable and agreement with that obtained in the experimental work of (Farhat, et al. 2016) [28]. Moreover, spectral absorbance of alloy Al7075 is plotted in Figure 5. The data are measured for the sample with opaque surface represented in Figure 2. The figures show different behaviors observed for this sample at the same wavelengths considered in Figure 3 and Figure 4. Peak values are obtained in the absorbance in visible-region (Vis) about $(800 \mathrm{~nm}$ ) with gradually decreasing in the longer wavelength (IR-region), in which the absorbance becomes with less value. It is seen that, an anodic oxide coating can turn the reflective surface of aluminum into significantly dark, by 
absorbing most of the impinging visible light. Figure 6 shows the percent reflectance of this sample against the wavelength. Opposite behavior is observed for the reflectance spectra. The figure is similar to the reflectance behavior from black surface coatings. The low-reflectance region extends from $300 \mathrm{~nm}$ to $800 \mathrm{~nm}$ and more reflectance is obtained for all wavelengths longer than $1000 \mathrm{~nm}$. These results are useful for decreasing unwanted visible radiation in infrared equipment.

\section{Surface Morphology}

The results of the experiments can be identified by the check of the thickness and surface structure of the anodic oxide films on the samples. So, the morphology of the oxide surface for the samples is examined with SEM under the effects of the anodization and sealing processes. Figure 7 shows SEM images of Al6061 anodized surface before (Figure 4(a)) and after sealing process

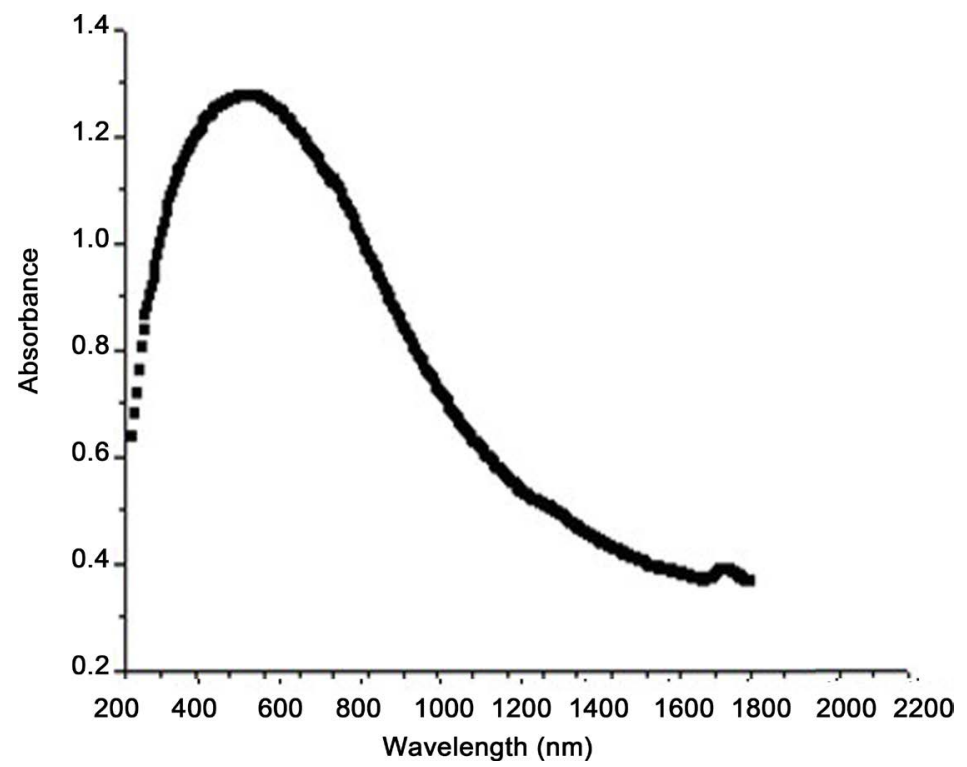

Figure 5. Absorbance of alloy Al7075.

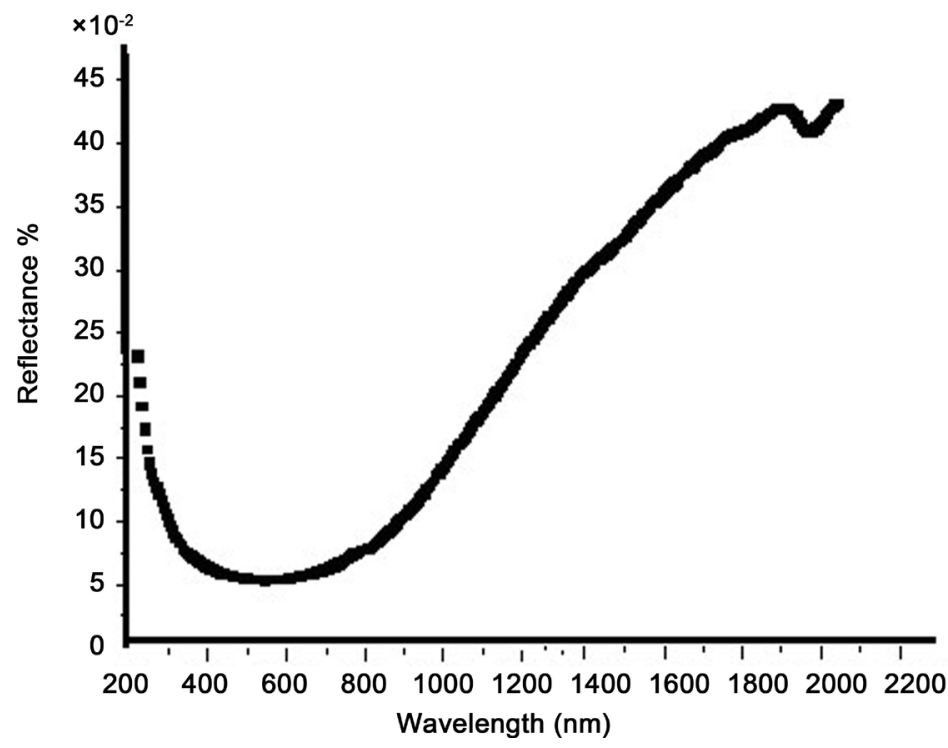

Figure 6. Spectral reflectance of alloy Al7075. 
(Figure 4(b)). Before sealing, some of pores and cracks are observed and distributed on the surface area. After sealing, these pores are relatively diminished and the surface is seen with more flatness and uniformity.

In Figure 8, SEM images are taken for the Al-surface for the same conditions considered in Figure 7. From the figure, it is noticed that, more cracking and incisions are observed (Figure 8(a)) before sealing, while it is approximated seemed to be vanished after sealing process (Figure $8(\mathrm{~b})$ ). It is logical to expect that anodization of aluminum having impurities leads to defects because of the difference of volume expansion of impurities than of aluminum.

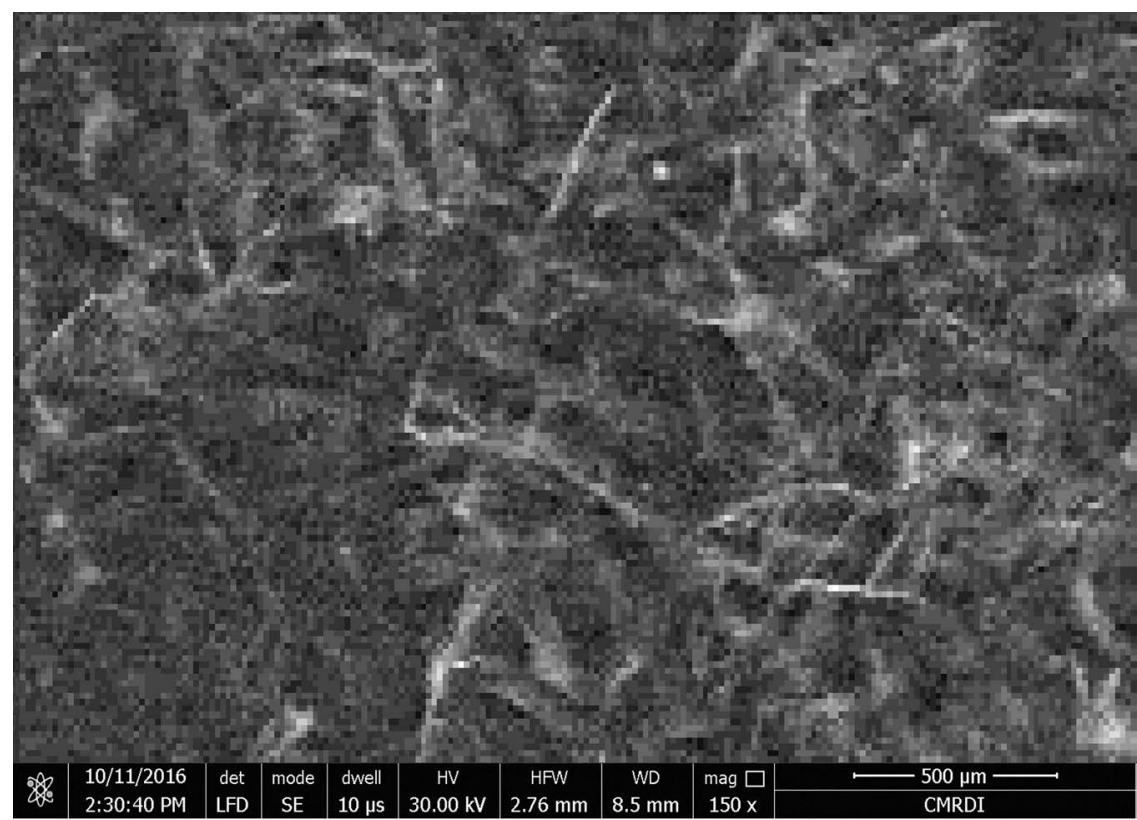

(a)

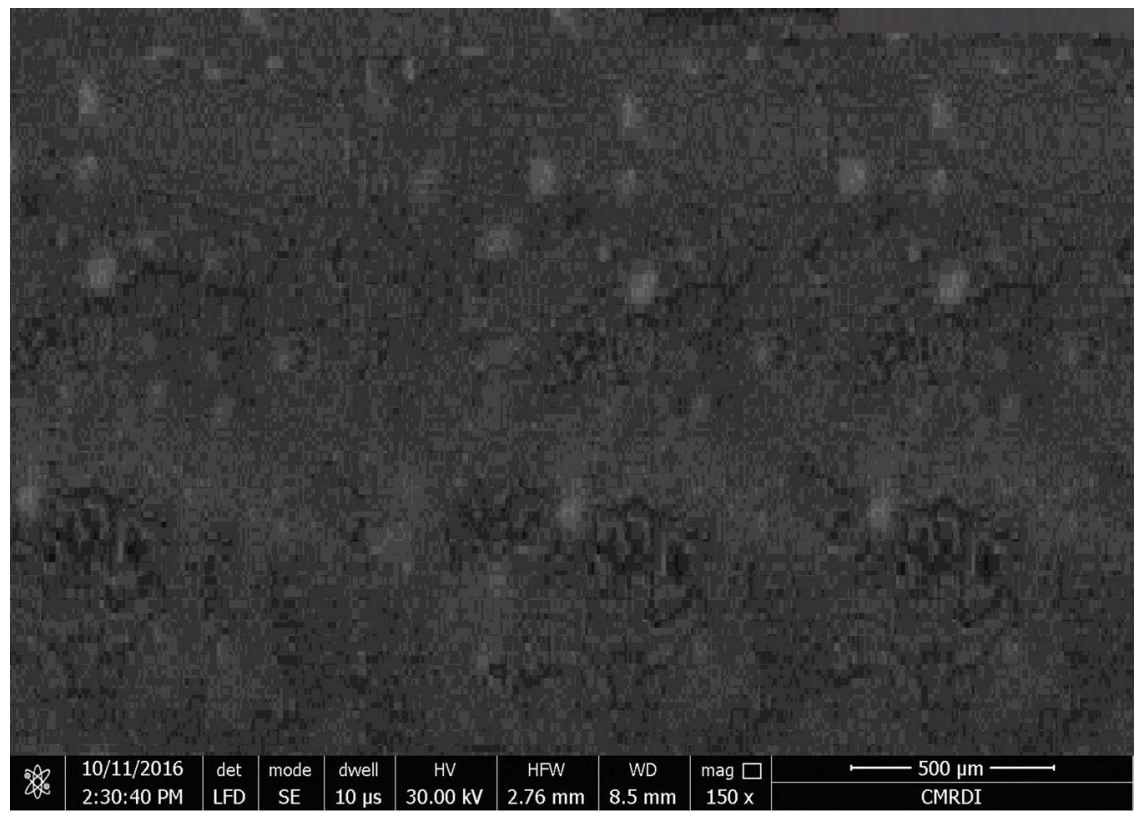

(b)

Figure 7. SEM images of alloy Al6061 (a) before and (b) after sealing process. 


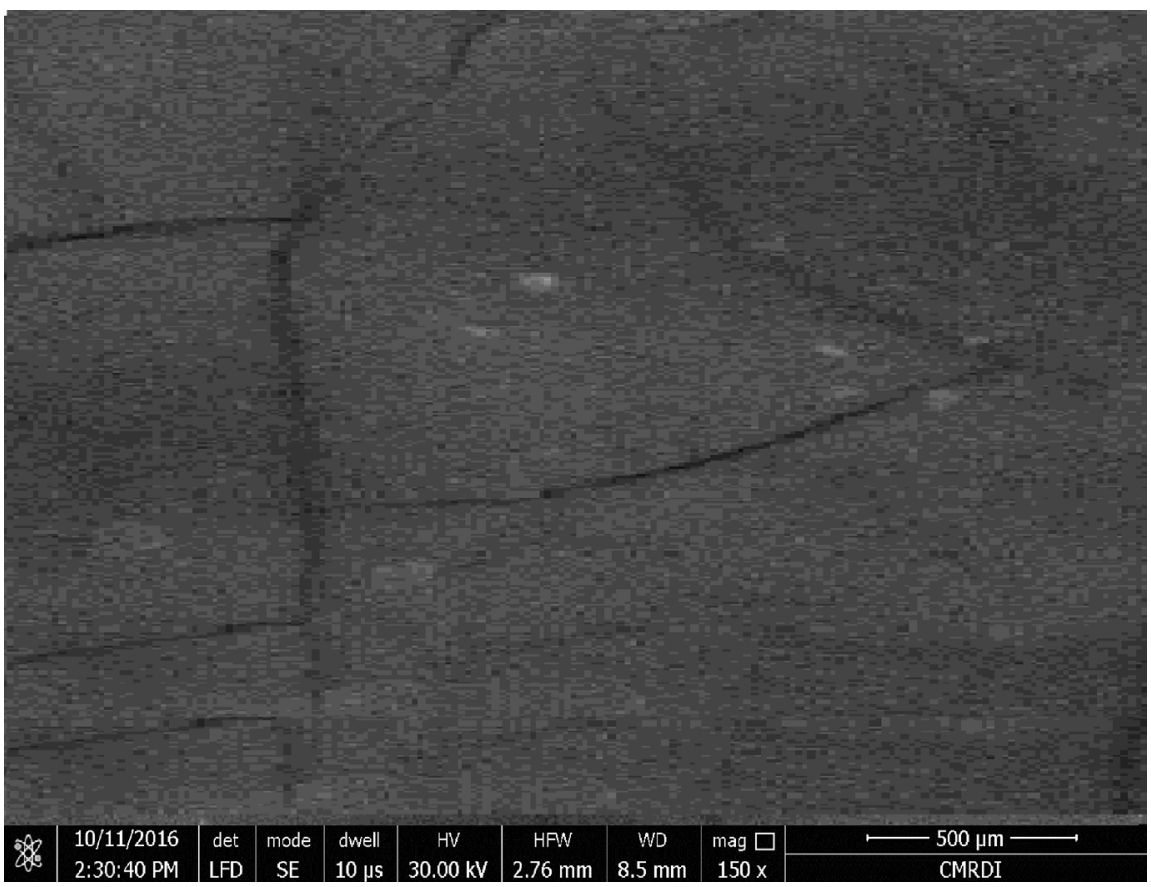

(a)

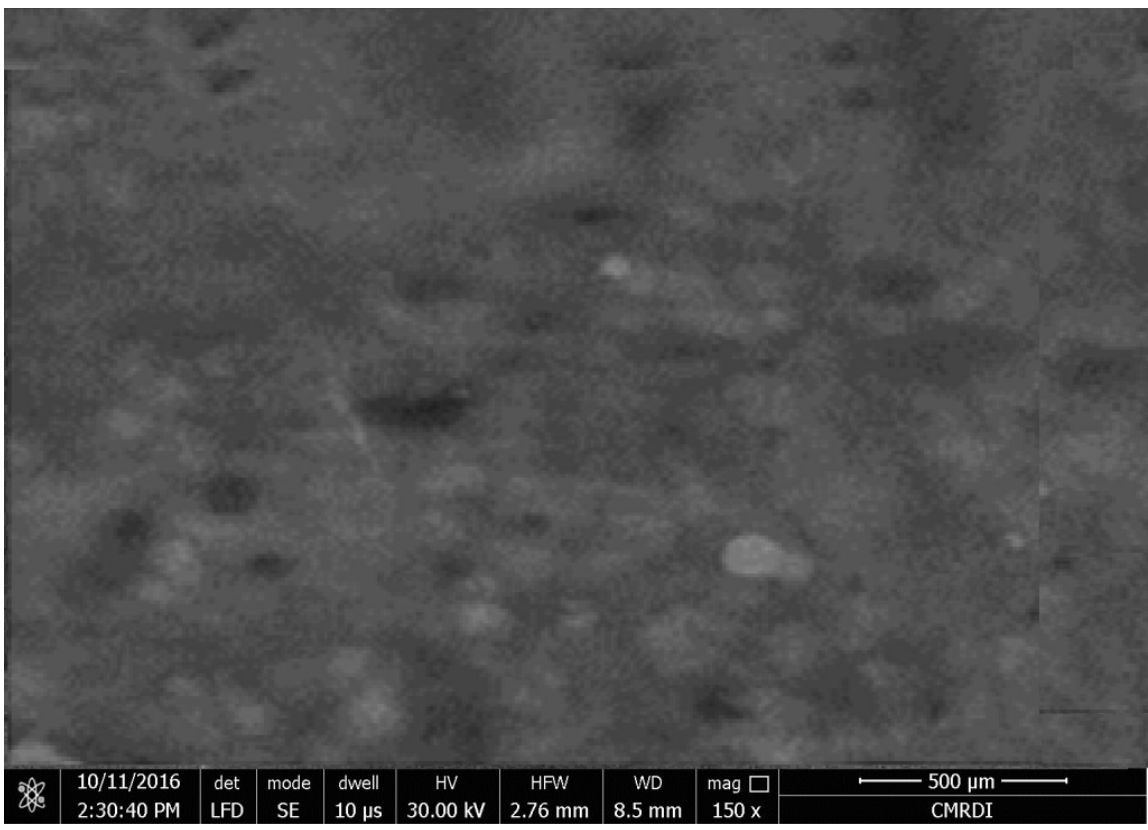

(b)

Figure 8. SEM images of $\mathrm{Al}$ (a) before and (b) after sealing process.

\section{Conclusions}

Anodic oxide of aluminum and different types of aluminum alloys as Al2024, Al6061 and Al7075 are prepared by electrochemical method using the solution of sulfuric acid. The effects of different anodizing conditions and parameters are studied. The anodic films are formed on metal surfaces with different thicknesses. To enhance the anodic coating surfaces, we use water-sealing process to seal the porous coatings and find that, the oxide porosity decreases with sealing by pore-filling 
technique, leading to the oxide layer with more flatness and uniformity. The results show that, the increasing current density and lowering operating temperatures lead to more dense coating. Besides, the increasing of the thickness with increase in acidic concentration is obtained and found greater than that obtained with less acid concentration. The examined optical properties and spectral analysis for the samples demonstrate the dependency on the alloy elements. Morphology and optical characteristics are found to be comparable with the previous studies.

These results can be useful to obtain optimum anodizing conditions leading to the anodic film formation improving high corrosion resistance and with the best optical characteristics and properties for long-duration exposure to spacecraft external environments.

\section{References}

[1] Danford, M.D. (1994) The Corrosion Protection of Several Aluminum Alloys by Chromic Acid and Sulphuric Acid Anodizing. NASA, Technical Paper, 3490.

[2] Govindaraju, H.K., Jayaraj, T., Sadanandarao, P. and Venkatesha, C.S. (2009) Evaluation of Mechanical Properties of As-Cast Al-Zn-Ce Alloy. Materials \& Design, 31, 524-529.

[3] He, C.C. and Heslin, T.M. (1995) Preventing Cracking of Anodized Coatings. NASA Technical Memorandum, 104622.

[4] Teichman, L.A., Slemp, W.S. and Witte, W.G. (1992) Evaluation of Selected Thermal Control Coatings for Long-Life Space Structures. NASA TM-4319.

[5] Henkener, J.A. (2003) Process Specification for the Anodizing of Aluminum Alloys. NASA PRC-5006 Rev. C.

[6] Dursch, H. (1988) Chromic Acid Anodizing of Aluminum Foil. NASA Technical Reports Server (NTRS), 988-01-01.

[7] Goueffon, Y., Arurault, L., Mabru, C., Tonon, C. and Guigue, P. (2009) Black Anodic Coatings for Space Applications: Study of the Process Parameters, Characteristics and Mechanical Properties. Journal of Materials Processing Technology, 209, 5145-5151. https://doi.org/10.1016/j.jmatprotec.2009.02.013

[8] Le, H.G., O’Brien, D.L. and Douglas, M. (1993) Process for Producing a High Emjttance Coating and Resultingarticle. United States Patent No. 5217600.

[9] Black, T.P., Schneider, T.A., Vaughn, J.A. and Tiepel, B.R. (2006) Plasma-Induced Dielectric Breakdown of Anodized Aluminum Surfaces. 44th AIAA Aerospace Sciences Meeting and Exhibit, Reno, Nevada, 9-12 January 2006, AIAA 2006-871. https://doi.org/10.2514/6.2006-871

[10] Schneider, T.A., Carruth Jr., M.R., Finckenor, M.A., Vaughn, J.A., Heard, J. and Ferguson, D. (2001) An Experimental Investigation of the Effects of Charging on the International Space Station. Spacecraft Charging Technology. Proceeding of the 7 th International Conference on Spacecraft Charging Technology, Noordwijk, the Netherlands, 23-27 April 2001, 405.

[11] Shrestha, S. and Hutchins, S. (2009) Microstructural and Corrosion Characteristics of PEO Treated UNS A97075, A92099 and A92195 Alloys. Department of Defense Corrosion Conference, Washington DC, 10-14 August 2009.

[12] Grilli, R. (2010) Conversion Coatings for Aluminium Alloys: A Surface Investigation for Corrosion Mechanisms. PhD Thesis, Surrey Materials Institute and Faculty of Engineering \& Physical Sciences, University of Surrey, Surrey. 
[13] Fletcher, K. (2008) Assessment of Chemical Conversion Coatings for the Protection of Aluminum Alloys. ESA STM-276.

[14] Shang, Y., Wang, L., Liu, Z., Niu, D., Wang, Y. and Liu, C. (2016) The Effects of Different Sealing Techniques for Anodic Film of Al-12.7Si 0.7 Mg Alloys. International Journal of Electrochemical Science, 11, 5234-5244. https://doi.org/10.20964/2016.06.85

[15] Ferguson, D.C., Vayner, B.V., Galofaro, J.T., Hillard, G., Vaughn, J. and Schneider, T. (2006) NASA GRC and MSFC Space Plasma Arc Testing Procedures. IEEE Transactions on Plasma Science, 34, 1948-1958. https://doi.org/10.1109/TPS.2006.879093

[16] Abdel-Aziz, Y.A., Abd El-Hameed, A.M., El-Tokhy, F.S., Ghitas, A., Selim, I. and Sabry, M. (2013) Ground-Based Simulation for the Effects of Space Plasma on Spacecraft. Advances in Space Research, 51, 133-142. https://doi.org/10.1016/j.asr.2012.07.026

[17] Anodic Coating for Aluminum and Aluminum Alloys (1993) Part of MIL-A-8625F.

[18] Gazapo, J.L. and Gea, J. (1994) Anodizing of Aluminium. TALAT Lecture 5203. EAA (European Aluminium Association).

[19] Le, H. and O’Brien, D.L. (1993) Process for Producing a High Emjttance Coating and Resulting Article. United States Patent 5217600.

[20] Kallenborn, K.J. and Emmons, J.R. (1995) Thin-Film Sulfuric Acid Anodizing as a Replacement for Chromic Acid Anodizing. NASA Technical Reports Server (NTRS).

[21] Franco, M., Anoop, S., Uma Rani, R. and Sharma, A.K. (2012) Porous Layer Characterization of Anodized and Black-Anodized Aluminum by Electrochemical Studies. ISRN Corrosion, 2012, Article ID: 323676.

[22] Alwitt, R.S., McClung, R.C. and Jacobs, S. (1992) Anodized Aluminum Coatings for Thermal Control, Part I: Coating Process and Stresses. AIAA-922158-CP, AAIA Technical Papers (A92-31285 12-23), Washington DC, 39-45.

[23] Jeon, S. and Chung, W. (2014) An Influence of Current density and Temperature about Anodic Oxidation Film Properties of Al Die-Casting. Advanced Science and Technology Letters, 64, 4-8. https://doi.org/10.14257/astl.2014.64.02

[24] Bensalah, W., Feki, M., Wery, M. and Ayedi, H.F. (2010) Thick and Dense Anodic Oxide Layers Formed on Aluminum in Sulphuric Acid Bath. Journal of Materials Science \& Technology, 26, 113-118. https://doi.org/10.1016/S1005-0302(10)60018-7

[25] Mubarok, M., Sutarno, W. and Wahyudi, S. (2015) Effects of Anodizing Parameters in Tartaric-Sulphuric Acid on Coating Thickness and Corrosion Resistance of Al2024 T3 Alloy. Journal of Minerals and Materials Characterization and Engineering, 3, 154-163. https://doi.org/10.4236/jmmce.2015.33018

[26] Sigamani, S., Thangavelu, P.R., Srinivasan, K.N. and Selvam, M. (2014) Studies on AC Anodizing of Aluminum in Sulfuric Acid Electrolyte Containing Sodium Sulfate. International Journal of Innovative Research in Science, Engineering and Technology, 3, 13869-13875.

[27] Derman, M., Abd Halim, M. and Shamsudin, S. (2009) The Influence of Sulphuric Acid Concentration on Hard Anodizing Process on Power Metallurgy Al-Mg. Journal of Nuclear and Related Technologies, 6, 224-229.

[28] Farhat, M., et al. (2016) Mirror-Backed Dark Alumina: A Nearly Perfect Absorber for Thermo Electronics and Thermo Photovoltaics. Scientific Reports, 6, Article ID: 19984. https://doi.org/10.1038/srep19984 
Submit or recommend next manuscript to SCIRP and we will provide best service for you:

Accepting pre-submission inquiries through Email, Facebook, LinkedIn, Twitter, etc. A wide selection of journals (inclusive of 9 subjects, more than 200 journals)

Providing 24-hour high-quality service

User-friendly online submission system

Fair and swift peer-review system

Efficient typesetting and proofreading procedure

Display of the result of downloads and visits, as well as the number of cited articles Maximum dissemination of your research work

Submit your manuscript at: http://papersubmission.scirp.org/

Or contact msa@scirp.org 